\title{
EDUCAÇÃO E RAZOABILIDADE NA TEORIA DA JUSTIÇA DE RAWLS
}

Sidney Reinaldo Silva*

\begin{abstract}
RESUMO
A escola tem que proporcionar condições para que todos adquiram as virtudes políticas? Este texto discute um prisma para se analisar, propor e avaliar práticas e concepções educacionais. Nas sociedades modernas, os conflitos entre concepções de mundo e de vida mostram o quanto estas podem se tornar incompatíveis e mesmo irreconciliáveis. Na escola, isso tem uma repercussão especial, mas não muito diferente do que ocorre em outros espaços públicos. Na definição dessas propostas, ocorrem disputas entre diversos valores e princípios para a formação humana. Rawls propõe um esquema que possibilita refletir sobre formas de lidar com a divergência dessas concepções. Mostro que tanto o que vai ser ensinado na escola quanto a forma como se decide sobre isso podem ser enfocados a partir da concepção de razoabilidade proposta pelo autor, apesar das críticas às quais estão sujeitos os seus pressupostos ético-políticos.
\end{abstract}

PALAVRAS-CHAVE: Razoabilidade. Escola. John Rawls.

\begin{abstract}
Does school offer "reasonable" moral education? In which way can it be donne? This paper analyses a prism in which this kind of

* Doutor em Filosofia e Professor do Programa de Pós-Graduação em Educação da Universidade Tuiuti do Paraná.
\end{abstract}

Educ. e Filos., Uberlândia, v. 21, n. 41, p. 43-60, jan./jun. 2007. 
question can be discussed: the Rawlsian theory of justice as fairness. In modern societies, different conceptions of moral can become incompatibles and even inconciables. Conflict between them reverberates in school like in others publics spheres. There are a lot of educational conceptions about the way of teaching political virtues and values. In a pluralistic society, moral conflict is not so easy to deal with. Rawls offers a philosophical scheme to reflect about moral desagreement. The rawlsian conception of reasonability, dispite the problems pointed out by his critics, keep being a relevant parameter for discussing citizenship education.

KEYWORDS: School. Reasonability. Rawls.

Reasonables persons see that the burdens of judgment set limites on what can be reasonably justified to others, and so they endorse some form of liberty of conscience and freedom of thought. It is unreasonable for us to use political power, should we possess it, or share it with others, to repreess compreensive views that are not unreasonable (RAWLS, 1993, p. 61).

Of course, a society may also contain unreasonable and irrational, and even mad, compreensive doctrines. In their case the problem is to contain them so that they do not undermine the unity and justice of society (1993, p. xvii).

Neste texto, mostro que a teoria da justiça como eqüidade e o liberalismo político de John Rawls são concepções filosóficas e éticas importantes para se pensar o tipo de cidadão que se pretende formar nas escolas. Suas concepções tornam-se um contraponto necessário para se pensar a relação entre pluralidade e espaço público. A escola fundamental é um lugar apropriado para desenvolvimento do senso moral, das virtudes políticas, como a tolerância, o respeito mútuo, a reciprocidade, e o senso de eqüidade e civilidade. Com isso, ela fortalece formas de pensar e sentir que sustentam a cooperação eqüitativa entre cidadãos. Mas, nas democracias

Educ. e Filos., Uberlândia, v. 21, n. 41, p. 43-60, jan./jun. 2007. 
constitucionais, não cabe à escola obrigatória promover uma doutrina abrangente ${ }^{1}$ como única e exclusiva fonte de valores para a formação da cidadania. Ela deve proporcionar condições para que todos adquiram as virtudes políticas, sem, contudo, atacar os valores ou promover de forma unilateral ideários específicos de uma doutrina abrangente. Na escola, deve-se discutir como ela incentiva ou desencoraja certas doutrinas abrangentes e seus modos de vida, e se a maneira como isso é feito seria justa. Mas, numa democracia constitucional, tal como John Rawls a concebe, a educação básica obrigatória deve promover a familiarização das pessoas com a cultura política pública.

Nas sociedades modernas, diferenças entre concepções abrangentes mostram o quanto elas podem se tornar incompatíveis, conflitantes e mesmo irreconciliáveis. Na escola, isso se repercute de modo especial. Assim, existem diversificadas propostas de ensino, de método e recurso pedagógico para se formar pessoas. $\mathrm{Na}$ definição dessas propostas, ocorrem disputas entre diversos matizes de concepções individualistas e comunitaristas de formação moral (MARQUES, 1998). John Rawls propõe um esquema, baseado na razão prática, que, segundo ele, possibilitaria decidir a respeito da divergência dessas concepções na esfera pública. Nesta análise, apresento os seguintes aspectos de seu pensamento: razão prática e a razoabilidade, os princípios para a sociedade justa, pluralismo e consenso, educação e razoabilidade.

1 Uma doutrina abrangente é, para Rawls (1993), uma concepção geral que se aplica universalmente a um vasto aspecto da vida ou a um grande leque de objetos. Ela organiza valores de modo que sejam compatíveis entre si e expressem uma visão de mundo inteligível. Doutrinas abrangentes são sistemas e perspectivas de vida coerentes dados por visões de mundo, de pessoa e de sociedade, valores, e crenças comuns sobre como as coisas devem ser. As pessoas têm afeições, saberes e devoções, dos quais não poderiam se distanciar para avaliá-los com objetividade. Elas seriam mesmo impensáveis sem vínculos de lealdade, convicções religiosas, filosóficas e morais. Pessoas se expressam por meio de concepções abrangentes.

Educ. e Filos., Uberlândia, v. 21, n. 41, p. 43-60, jan./jun. 2007 


\section{Razão prática, sociedade justa e razoabilidade}

A razão prática, para John Rawls, expressa-se, sobretudo, como capacidade de distinguir o ponto de vista público de perspectivas não públicas. Com isso, a pessoa pode representar, pensar, questionar e argumentar no interior de uma concepção política $^{2}$, tornando-se apta para participar da vida pública. O exercício da razão prática ocorre, por exemplo, na imaginação de um hipotético estado de natureza a partir do qual se poderia definir a forma mais justa para se organizar uma sociedade. Trata-se de um ponto de vista comum para se argumentar quando cidadãos discutem e deliberam no âmbito político. Em sua obra Uma teoria da justiça, o autor fala de uma fictícia posição original ${ }^{3}$ como um esquema ético em que as pessoas são tomadas como livres e iguais, o que facultaria o estabelecimento de princípios para uma sociedade justa. Tal como a posição original, a concepção do campo político torna-se um dispositivo ético para se construir uma perspectiva comum capaz de modular o consenso entre os cidadãos. ${ }^{4}$

John Rawls destaca duas capacidades morais: a racionalidade e a razoabilidade, respectivamente, a capacidade de conceber um

2 A concepção política possibilita a articulação de valores e formas de argumentar específicos e não de todos os valores a todas as formas de argumentar. Ela se baseia em princípios da razão prática e com concepções de sociedade e pessoa deles decorrentes.

3 Posteriormente Rawls concebe também o construtivismo político: "The principles of political justice are the result of a procedure of construction in wich rational persons (or their representatives), subject to reasonable conditions, adopt the principle to regulate the basis struture of society. The principles that issues from a suitable procedures of construction, one that properly expresses the requisite principles and coneptions of practical reason, I think of as reasonable. The judgments those principles support are also reasonable“ (1993, p.xx). Trata-se de um esquema segundo o qual a discussão pública sobre as questões políticas fundamentais podem ser razoavelmente decididas, tais como as que se referem às questões constitucionais essenciais e de justiça básica.

4 "To use a current phrase, the political is a module, an essential constituent part, that fits into and can be suported by various reasonables comprehensive coctrines that endure in the society regulated by it" (1993, p. 12)

Educ. e Filos., Uberlândia, v. 21, n. 41, p. 43-60, jan./jun. 2007. 
bem, um projeto de vida e de buscar os meios adequados para realizálos e a capacidade de propor e aceitar acordos justos, de negociar regras e normas com ponderação e reciprocidade. A primeira mantém correlação com a razão estratégica e a segunda com a civilidade e a capacidade de negociar consensos e contratos justos. A razoabilidade diz respeito a valores da esfera política, e exige uma formação que favoreça o florescimento de virtudes políticas sem as quais a pessoa não poderia participar do debate público. O modo como devem ser formadas as capacidades morais na escola exige a negociação razoável entre os profissionais da educação. Assim, ao se decidir, na escola obrigatória, como e quais virtudes cívicas serão ensinadas para se formar cidadãos razoáveis, exige-se razoabilidade.

John Rawls (1993, pp. 5-6) apresenta dois princípios para regular a sociedade bem-ordenada. O primeiro princípio (o da liberdade) propõe que todas as pessoas têm igual direito a um projeto inteiramente satisfatório de direitos e liberdades básicas iguais para todos, desde que compatível com todos os demais; em tal projeto, somente as liberdades políticas deverão ter a garantia de eqüidade. O segundo princípio, dividido em duas partes, estabelece que as desigualdades sociais e econômicas devem satisfazer dois requisitos: devem estar vinculadas a posições e cargos abertos a todos, em condições de igualdade eqüitativa de oportunidades (princípio da igualdade de oportunidades); devem representar o maior benefício possível para os membros menos privilegiados da sociedade (princípio da diferença).

Esses seriam os princípios fundamentais segundo os quais a constituição de um país seria formulada, e que, a partir dela, regulariam a produção da legislação ordinária, os atos do executivo e do judiciário. Os princípios possibilitam também o controle das políticas sociais. O princípio da diferença seria aquele cuja observação levaria a sociedade rumo à igualdade. Contudo, como mostra Parijs (2003, p. 210), Rawls oferece várias razões para não se usar o princípio da diferença nas decisões a respeito da justiça entre gerações assim como entre povos. Além do mais, o princípio da diferença não é recomendado, também, para regular a conduta individual, mas apenas para as instituições (PARIJS, p. 233). 
Para Rawls, esses princípios deveriam ser aceitos por pessoas racionais e razoáveis como sendo os alicerces éticos para se regular as estruturas básicas da sociedade, ou seja, a forma como o sistema de instituições distribui benefícios e encargos numa sociedade. Além de tais princípios da justiça serem apontados como coerentes com a cultura pública ocidental, eles são tomados também como expressão do senso de justiça dos seres humanos, o qual desabrocharia com uma educação adequada.

\section{A formação da razoabilidade}

Para Rawls, o senso de justiça estaria presente no ser humano em decorrência da evolução da espécie. Se este traço não fosse selecionado, certamente a humanidade não teria sobrevivido. Esse senso de justiça tende a se desenvolver nas pessoas que não sofreram doenças ou desvios no interior da família e dos processos educacionais. Contudo, em sociedades injustas, o florescer da competência moral poderia estar comprometido. Mas, de qualquer forma, haveria uma tendência na humanidade segundo a qual pessoas que crescessem sob instituições justas adquiririam o senso de justiça.

O primeiro princípio da justiça garante o direito à liberdade, protegendo a autonomia como um valor essencial para a realização do indivíduo. Cabe a uma sociedade bem ordenada garantir as condições básicas para uma vida autônoma. Para isso, deve-se garantir às pessoas uma lista de bens primários, como renda, riquezas, oportunidades de acesso a posições de autoridades e cargos valorizados pela sociedade. Se tais bens não forem eqüitativamente distribuídos, a liberdade não teria o mesmo valor para todos, pois a autonomia exige o acesso eqüitativo a um mínimo de benefícios sociais. Ainda que esse mínimo possa variar conforme a concepção de pessoas de uma sociedade, ${ }^{5}$ sem ele não se poderia

5 "Equal relation at the highest level favors, when life-prospects are involved, a social minimum based on an idea of reciprocity over one that only covers the human needs

Educ. e Filos., Uberlândia, v. 21, n. 41, p. 43-60, jan./jun. 2007. 
falar de dignidade ou de uma base objetiva para a construção da auto-estima das pessoas.

A garantia das condições básicas para uma vida autônoma depende de uma educação que faculte, ao longo da vida, qualificação profissional, sem a qual não se pode garantir a igualdade de oportunidades de acesso a empregos e cargos, e que possibilite desenvolvimento das capacidades morais, indispensáveis para a vida cívica. O direito à educação torna-se então fundamental numa sociedade bem ordenada. Os recursos públicos destinados à educação devem ser negociados de modo que não se desrespeite os princípios da justiça. A educação compulsória precisa ser publicamente controlada para se garantir o desenvolvimento das capacidades morais, bases da autonomia racional e razoável da pessoa.

Nem todas formas de moralidade são razoáveis, assim como nem todas as formas de se justificá-las e defendê-las o são. Os processos pedagógicos que suprimem a autonomia humana são condenáveis do ponto de vista da justiça como eqüidade. Ela rejeita o ensino que manipula o comportamento ou que reprime. ${ }^{6}$ Cabe ao educador perguntar a si mesmo se acredita que a moral (princípios, valores, concepções de pessoa, sociedade, justiça e vida boa) que propõe, como devendo ser reconhecida como válida e, enquanto tal, ensinada, seria dada diretamente para apenas alguns eleitos, tais como sacerdotes, pastores e profetas ou para todas as

essential to a decent life. Here we see how the appropriate concept of a social minimum depends on the content of the public political culture, which in turn depends on how political society itself is conceived by its political conception of justice. The concept of the apropriate minimum is not given by the basic needs of human nature taken psycologically (or biologically) apart from any particular social world. Rather, it depends on the fundamental intuitive ideas of person and society in terms of which justice as fairness is laid out" (RAWLS, 2003b, p. 132).

6 "A person's sense of justice is not a compulsive psycological mechanism cleverly installed by those in authority in order to insure his unswerving compliance with rules designed to advance their interests. Nor is the process of education simply a causal sequence intended to bring about as an end result the appropriate moral sentiments (2003a, p. $452)$. 
pessoas razoáveis e conscienciosas; se ela deriva de uma fonte externa, de uma ordem de valores existente no intelecto de Deus ou surge na especificidade humana, em sua razão e sentimentos, juntamente com as condições de vida em sociedade; e também perguntar se a pessoa é levada a cumprir suas obrigações por algum tipo de motivação externa, como sanções divinas, o aparato repressor estatal, ou se ela possui em si mesma motivos suficientes que a levariam a agir como deve, sem a necessidade de ameaças externas (1993, p. xxvi-xxvii).

Rawls inclina-se pelas segundas alternativas, reconhecendo que essas são as opções de pessoas politicamente liberais, ou seja, razoáveis. No texto Uma teoria da Justiça, ele se mostra afinado com a concepção construtivista da formação moral, sendo claramente partidário das idéias de Rousseau, Kant, Piaget e Kohlberg. É admitida a sequiência de três estágios, conforme a qual se davam as seguintes etapas: moralidade de autoridade, de grupo e de princípios. Esses são momentos de formação do senso moral, em que progressivamente o indivíduo aprenderia a confiar nos outros, especialmente naqueles por quem foi bem tratado; a ver as questões a partir de perspectivas diferentes; a ser capaz de reciprocidade; a conceber uma perspectiva comum mais ampla, que se estenderia para além daquela de sua família e nação, enfim, de se tornar moralmente autônomo.

\section{Pluralismo liberal e razoabilidade}

Mas Rawls, no texto O liberalismo político, reconhece que a concepção de formação humana liberal construtivista é "abrangente" e não poderia ser endossada, enquanto tal, como base da perspectiva política. Por mais que ela fosse afinada com a concepção política da justiça como eqüidade, ela não poderia ser adotada como padrão a ser ensinado em escolas obrigatórias. $\mathrm{O}$ liberalismo político de Rawls não se confunde com os liberalismos abrangentes de Kant e de Mill. Ele não afirma que todos os valores morais devessem ser construídos, não só na perspectiva do político, mas também na vida cotidiana das pessoas, como admite Kant.

Educ. e Filos., Uberlândia, v. 21, n. 41, p. 43-60, jan./jun. 2007. 
Nem muito menos seria razoável supor que todos devessem ser autônomos o tempo todo. Algumas pessoas poderiam submeter livremente sua conduta a ditames de igrejas e associações às quais se filiam, sem, contudo, deixarem de ser razoáveis.

A razoabilidade, segundo Rawls, é necessária para a convivência democrática numa sociedade pluralista, pois ela possibilita o entendimento mútuo quando questões de justiça social estão em jogo. Nesse sentido, a capacidade de ser razoável possibilitaria a construção do que o filósofo denominou consenso sobreposto.

A idéia de um consenso sobreposto pressupõe que nenhuma concepção abrangente, por mais que penetrasse no interior da "cultura pública", poderia constituir-se numa base comum para a construção de uma democracia constitucional e para conceber princípios de justiça para o ordenamento social. Uma comunidade unida pela aceitação de uma única doutrina abrangente exigiria o uso do poder opressivo estatal para manter a comunhão política, ocorrendo, então, o fato da opressão. Toda forma de intolerância seria uma prática não razoável. O pluralismo seria uma realidade histórica que teria vindo para ficar. Não se trataria de um fenômeno passageiro que seria superado no momento em que uma determinada concepção abrangente tomasse o poder. Contudo, o pluralismo não é irredutível na perspectiva pública ou no campo político, no qual as pessoas são reconhecidas como livres e iguais, o que é garantido por uma educação que possibilite o desenvolvimento adequado das capacidades morais.

A questão é a de saber como os cidadãos, que continuassem profundamente divididos em relação às doutrinas religiosas, filosóficas e morais, poderiam manter, apesar disso, uma sociedade democrática e estável. Para que isso ocorra, os cidadãos precisam ser concebidos como livres e iguais numa perspectiva passível de ser compartilhada por todos. Essa perspectiva, tal como proposta por Rawls, não é uma concepção religiosa ou filosófica da pessoa, mas pública e normativa. Adaptada a um esquema político de justiça e não a uma doutrina abrangente, o filósofo propõe uma concepção da pessoa como uma unidade básica de pensamento, 
deliberação e responsabilidade, capaz de ser um membro normal e cooperativo de uma sociedade justa (1993, p. 18). Nesse sentido político, publicamente, os cidadãos se reconhecem como livres e iguais.

O prisma político é um módulo autônomo, com valores específicos, no qual as concepções abrangentes razoáveis se ajustam, num processo de formação para a vida pública. A concepção política é enfocada como educadora, "as educator" (1993, p. 70). Não se trata porém de uma concepção mínima da educação cívica, minimal conception of civic education, como mostra Costa (2004), em que se procuraria reduzir ao máximo o que seria ensinado como base comum de valores para não interferir demasiadamente na formação moral das crianças, evitando, com isso, interferir em prerrogativas das famílias e das comunidades. A concepção política de formação moral não se define pelo quanto a ser ensinado. Ela se caracteriza pela forma como modula e cria uma superfície de interface entre as concepções abrangentes.

Uma sociedade justa deveria admitir a existência de várias doutrinas abrangentes razoáveis ainda que conflitantes, cada qual com suas próprias concepções de bem e cada qual coerente com a concepção política de pessoa. Assim produzir-se-ia um equilíbrio entre valores políticos e não políticos, um consenso sobreposto (overlapping consensus) entre elas. A concepção política não é cética ou indiferente: embora tenha seus valores específicos, ela mantémse congruente com as concepções abrangentes (1993, p. 151).

Pessoas razoáveis são capazes de aprender e dominar os princípios da razão prática (1993, p. 112). Cabe ao ensino, como transmissor da cultura política pública, exercitar a razão prática familiarizando as pessoas com a razoabilidade. Deve se aprender quando e como discordar publicamente, e saber apresentar razões apropriadas para avaliar as instituições. O cidadão deve saber que nem todo valor passará no teste discursivo ou será um valor político, e que nem todo equilíbrio de valores é razoável. Aprenderia também que é inevitável e desejável que os cidadãos tenham visões diferentes do que vem a ser uma concepção política mais apropriada, pois a cultura política pública está fadada a conter diferentes idéias

Educ. e Filos., Uberlândia, v. 21, n. 41, p. 43-60, jan./jun. 2007. 
fundamentais, que podem ser desenvolvidas de formas diferentes. É necessário aprender que o contínuo debate ordenado entre elas é a forma mais confiável de descobrir qual é a mais razoável, se alguma o é.

\section{A razoabilidade na escola}

Na escola obrigatória, a teoria da justiça como eqüidade exige que, ente outras coisas, se ensine também a pessoa a conciliar os dois traços de identidade moral, o público e o privado. Com isso, o ensino levaria cada um a se entender criticamente como pertencendo a uma associação moldada por uma doutrina abrangente ou por fins intrínsecos definidos pelos interesses de associações às quais ela pertence. Quando adequadamente desenvolvida, a capacidade de ser razoável facultaria ao cidadão participar da vida democrática numa sociedade pluralista, na qual se pressupõe a coexistência de uma grande variedade de doutrinas abrangentes razoáveis. Conforme o liberalismo político de Rawls, a convivência democrática exige a capacidade de partilhar valores políticos tais como a tolerância e o reconhecimento das pessoas como livres e iguais, base para se definir um patamar justo de bens primários, como, por exemplo, a renda mínima, sem o que um esquema eqüitativo de cooperação não poderia ser instituído e mantido entre os cidadãos.

É destacável o estudo da escola conforme o pensamento de Rawls realizado por Gutmann (1987). Ela indica as características específicas de uma escola "multicultural", propondo uma formação cívica de modo a conciliar o "multiculturalismo", a democracia e o liberalismo. Escolas devem apresentar um propósito cívico partilhável por todos os cidadãos. Trata-se de buscar um equilíbrio entre as exigências exageradas de uniformidade do "universalismo transcendental" e as expectativas demasiadas restritas de uniformidade dos particularistas que propõem escolas separadas. Os valores da escola politicamente liberal "multiculturalista" seriam as liberdades básicas, a igualdade de oportunidades e a deliberação baseada em procedimentos justos.

Educ. e Filos., Uberlândia, v. 21, n. 41, p. 43-60, jan./jun. 2007 
Seria possível, na perspectiva política, a multiplicidade de práticas pedagógicas razoáveis, diversidade curricular, didática e metodológica. Caberia a cada escola escolher a que mais the parecesse adequada. Vou destacar algumas concepções de formação moral e discutir até que ponto elas podem ser consideradas razoáveis.

Associações do tipo nazistas ou fundamentalistas politicamente radicais seriam intolerantes. Isso por que elas negam os valores de uma democracia constitucional e os princípios da justiça como eqüidade. Se seus integrantes assumissem o poder, passariam a perseguir e negar direitos aos grupos e pessoas que divergissem de suas concepções de mundo. Qualquer pedagogia que favorecesse a formação de pessoas nazistas ou fundamentalistas radicais não seria admissível numa sociedade bem-ordenada, conforme propõe Rawls. Assim, poder-se-ia julgar o projeto político-pedagógico, o material didático, o plano de ensino de um professor e mesmo o conteúdo e a forma de se dar uma aula. Por mais autonomia que uma Constituição permitisse a um estabelecimento de ensino, ela não poderia ser usada para justificar semelhante prática pedagógica, a menos que a Carta Maior não tivesse sido elaborada conforme os princípios da justiça.

Já práticas baseadas no conceito pedagógico de esclarecimento de valores supõem que o professor não deve ensinar princípios e normas, nem muito menos intervir para mudar os valores dos alunos, mas apenas proporcionar ocasiões para que os mesmos entendam o tipo de moral que praticam. Caso possibilite o desenvolvimento de pessoas individualistas e relativistas, essa concepção de formação moral pode ser tolerada, pois nada impediria que essas pessoas participassem de um consenso sobreposto. Por mais relativista e individualista que seja determinada concepção abrangente, ela poderia aceitar os valores políticos, ainda que como não universais e convenientes. Contudo, se esse tipo de formação fomentar - ao incentivar o ceticismo e a indiferença - a recusa de votar, de pagar imposto, ou de apoiar instituições justas, ele ameaçaria os liames políticos de uma sociedade bem-ordenada. Esse ensino enfraqueceria o espírito de

Educ. e Filos., Uberlândia, v. 21, n. 41, p. 43-60, jan./jun. 2007. 
cooperação e reciprocidade. As escolas obrigatórias de uma sociedade bem-ordenada devem desencorajar essa prática de formação moral, caso ela tenda a perder a razoabilidade.

Práticas pedagógicas vinculadas às concepções religiosas, ainda que politicamente alienadas, podem ser também não razoáveis. É aceitável para a concepção política de Rawls que o ensino dos valores religiosos e da doutrina de uma determinada Igreja possa facilitar o desenvolvimento moral. Contudo, quando se visa formar cidadãos apartados do mundo, negando-lhes o acesso a conhecimentos essenciais para uma vida autônoma, e para o reconhecimento da própria identidade pública, pode se estar ferindo a liberdade de consciência. Isso se dá ao se inculcar que fora da Igreja não há salvação e que as demais práticas religiosas devem ser perseguidas por não se fundarem na verdade.

Os membros de uma seita religiosa alienada ou mesmo oposta à cultura do mundo moderno, ao evitarem as suas influências, não teriam o direito, segundo Rawls, de educar suas crianças como bem entendessem. Mas o liberalismo político não exige, como no caso do liberalismo abrangente de Kant e Mill, que essas crianças devam ser ensinadas conforme os valores liberais da autonomia e da individualidade para a totalidade da vida. Em contrapartida, há exigências mínimas que devem ser feitas pelo Estado. Deve-se exigir que a educação das crianças inclua o conhecimento de seus direitos constitucionais e civis, e ensine que a liberdade de consciência existe em sua sociedade e a apostasia não é ilegal. Assim, quando atingirem a maioridade, os membros da seita em questão poderiam continuar aderidos a ela, mas sem que isso ocorresse devido à ignorância de seus direitos básicos ou do temor de sofrer punição por ofensas inexistentes. Para Rawls, as crianças precisam ser preparadas para serem membros cooperativos da sociedade, bem como para sustentarem a si mesmas no futuro. Para isso, é necessário o acesso ao conhecimento da cultura pública e das formas de participar em suas instituições. As virtudes políticas devem ser incentivadas para que os membros de uma seita queiram cumprir os termos eqüitativos da cooperação social em suas relações com o resto da sociedade. 
Ao discutir a situação de minorias religiosas que escolhem levar uma vida apartada da sociedade, tal como a comunidade amish nos Estados Unidos, Rawls reconhece a validade, dentro de um certo limite, das exigências daqueles que, em concordância com as injunções de sua religião, desejam afastar-se da vida moderna, cujos valores mundanos são contrários aos princípios espirituais reconhecidos como superiores pela doutrina abrangente que professam.

Assim, seria possível ensinar os valores do liberalismo político, do civismo, sem influenciar as pessoas para o liberalismo abrangente. Haveria, então, diferenças de alcance e graus de generalidade entre essas duas concepções. Mas, de qualquer forma, Rawls admite que há riscos nesse processo. Ele reconhece que "as conseqüências inevitáveis dos requisitos razoáveis que se impõem à educação das crianças talvez tenham que ser aceitas com pesar" (1993, p. 200). Contudo, o liberalismo político não fomenta o ensino público das virtudes e valores próprios do liberalismo tradicional, como a exaltação da autonomia e da individualidade, da mesma forma que não aceita o cultivo oficial de qualquer outra doutrina moral. Ocorreria, no entendimento de Rawls, apenas uma sobreposição dos valores defendidos pelos liberais enquanto membros de uma doutrina abrangente, tal como Kant e Mill, com os valores políticos de uma sociedade bem-ordenada, segundo os quais as pessoas são reconhecidas como livre e iguais. Da mesma forma ocorreria a sobreposição de valores de outras doutrinas contrárias à ideologia liberal, como os ligados às idéias de cooperação e reciprocidade econômica, que são típicos do ideário moral socialista.

Na perspectiva do liberalismo político, as pedagogias ligadas ao socialismo não deixam de ser razoáveis. Para Rawls (2003), a concepção política da justiça como eqüidade poderia modular também a estrutura básica de povos socialistas. Ele acredita que essa concepção política seria compatível tanto com um regime de propriedade privada dos meios de produção quanto com um sistema econômico baseado na propriedade comum dos mesmos. Uma formação moral inspirada no ideário socialista só se tornaria

Educ. e Filos., Uberlândia, v. 21, n. 41, p. 43-60, jan./jun. 2007. 
não razoável quando formasse pessoas para negar as liberdades fundamentais ou que se dispusessem a tomar o poder e suprimir definitivamente as condições de possibilidade do pluralismo razoável, não importa se em nome da igualdade social ou da supressão da propriedade privada e da exploração. Contudo, Rawls (2003) admite que no caso de mudança no padrão de civilização decorrente das possibilidades inerentes à tradição de um povo, as liberdades poderiam ser momentaneamente suprimidas até que se efetivasse a transição do modelo de propriedade. Entretanto, concepções educacionais socialistas são razoáveis apenas quando se limitam a fomentar valores cooperativos aceitáveis para a sociedade ordenada conforme os princípios da justiça.

\section{Considerações finais}

A obra de Rawls tornou-se referência para os debates contemporâneos a respeito da justiça e da ética. Para saber se uma instituição educacional está em conformidade com o liberalismo político de Rawls, deve-se identificar se ela se orienta segundo o critério da eqüidade. Conforme a eqüidade, cada um deveria receber, de acordo com sua colaboração nas atividades cooperativas, naquelas em que diferentes pessoas atuam na produção de um bem.

Aqueles que produzem mais devem ganhar mais, pois, com isso, se manteria a eficácia e mesmo a competitividade daquele grupo perante os demais. Por outro lado, ainda segundo o critério de eqüidade, aqueles que ganham mais, em decorrência de uma atividade coletiva, devem contribuir com sua cota para que os menos favorecidos obtenham um mínimo necessário para que tenham acesso a um patamar de benefícios que lhes possibilite uma vida decente em relação aos demais e, com isso, tenham razões para aceitar e defender o esquema cooperativo. Nesse sentido, a eqüidade serve de valor guia tanto para se promover a competição, pois define que quem produz mais deve ganhar mais, como também para promover a cooperação, na medida em que 
estabelece que tal ganho deve ser relativo frente às necessidades dos menos eficientes, que sofrem em decorrência de fatores naturais e sociais, tais como o não acesso a uma formação profissional adequada. Para Rawls, no sentido cooperativo, a eqüidade correlaciona produtividade e reciprocidade econômica.

A questão moral da educação pode ser referida também ao princípio da diferença. A respeito dos valores a serem promovidos pela educação, a escola pode definir-se pelo ideário de favorecer os menos favorecidos como valor guia da formação moral. Assim, uma escola poderia não tolerar práticas pedagógicas que incentivem o individualismo e competição. Contudo, isso não pode ser feito transgredindo os dois primeiros princípios, o da liberdade igual e o da igualdade de oportunidades. Somente a partir dessa restrição, um gestor da educação pode entender que o ensino de valores solidários pode favorecer os menos privilegiados, pois futuramente contribuiria para a construção de uma sociedade mais justa e igualitária. Mas ao continuar tolerando práticas pedagógicas fomentadoras da competição e do individualismo, a sociedade bem ordenada de Rawls resguardaria o espaço para a reprodução do ethos capitalista.

Rawls (2003) propõe uma concepção política capaz de tornarse uma base pública que fosse aceita por todas as doutrinas abrangentes razoáveis, e que pudesse servir de eixo para se modular a formação do cidadão de modo racional e razoável. Mas parece que ele não leva em consideração a forma radical como as relações entre os mais favorecidos e os menos favorecidos impossibilitam o advento do razoável na sociedade capitalista. Para o autor, isso é mais uma disputa entre concepções liberais abrangentes e socialistas. Contudo, ainda que ele admita que sua teoria da justiça seja compatível com um regime de propriedade coletiva dos meios de produção, ele não abre mão do mercado enquanto fator fundamental para definir a alocação de recursos. O razoável referese à capacidade de propor e aceitar acordos justos, que muito lembra o mecanismo de negociação econômica. Mesmo a "virtude" é concebida como capital. As virtudes políticas, como a tolerância e a disposição de fazer concessões mútuas, a razoabilidade e o

Educ. e Filos., Uberlândia, v. 21, n. 41, p. 43-60, jan./jun. 2007. 
senso de justiça são vistas como um ativo público, no sentido de um capital comum. ${ }^{7}$

A concepção de razoabilidade de Rawls (2003) tornou-se alvo de críticas dos marxistas e dos relativistas pós-modernos. Para os primeiros, não liberais, não há sentido numa proposta de razoabilidade concebida no interior de uma sociedade definida pelas forças cegas do mercado, que produzem sempre uma iniqüidade incapaz de ser ajustada por mecanismos de redistribuição que não desmantelem de fato o processo básico de acumulação capitalista. Portanto, não faz sentido construir um ponto de vista moral comum baseado numa concepção de pessoa como "livre e igual" e, a partir dele, regular uma sociedade definida em última instância pelo mercado, fator gerador de desigualdades econômicas e sociais. Já para os relativistas pós-modernos, frente às irredutíveis diferenças de gênero, valores e concepções de mundo e a proposição de um ponto de vista comum seria uma quimera, e o correto seria aprender a fazer política sem consenso em diferentes e irredutíveis esferas políticas.

De qualquer forma, as idéias de John Rawls constituem-se em um contraponto que não pode ser ignorado tanto no que concerne à investigação das práticas institucionais, como as que ocorrem na escola, quanto para se definir um quadro normativo para a busca de entendimento ou para se lidar razoavelmente com o desentendimento, dentro de uma moldura pública não fragmentada.

7 “O termo capital é apropriado nesse ponto porque essas virtudes são constituídas lentamente com o passar do tempo e dependem não apenas das instituições políticas e sociais existentes (elas próprias constituídas lentamente), mas também da experiência dos cidadãos como um todo e de seu conhecimento do passado. Repetindo: como o capital, essas virtudes são depreciadas, por assim dizer, e devem se renovar constantemente, pela sua reafirmação e aplicação aos atos, no presente" (1993, nota 23, p. 157). 


\section{Referências}

COSTA, M. Victoria. Rawlsian Civic Education: Political not Minimal. Journal of Applied Philosophy, v. 21, January. 2004

GUtMANN, A. Democratic Education. Princeton: Princeton University Press, 1987.

MARQUES, Ramiro. Ensinar valores. Teorias e Modelos. Porto: Porto Editora, 1998.

PARIJS, Phelipe. Difference Principles. In: FREEMANN, Samuel. The Cambridge Companion to Rawls. Cambridge: Cambridge University Press, 2003.

RAWLS, John. A Theory of Justice. Revised Edition. Cambridge; Massachusetts: The Belknap Press of Havard University Press, $2003 a$.

1993.. Political Liberalism. New York: Columbia University Press, . Justice as Fairness. A Restatement. Cambridge; Massachustes; London; England: Harvard University Press, 2003b. . The Law of People. Harvard: Harvard Univesity Press, 2002. 